\title{
Teachers Perceptions of Gender Differences in Learning Styles in Pakistan
}

\author{
Tayyaba Bint-e- Mehmood \\ University of Central Punjab, Lahore, Pakistan \\ 1 - Khayaban-e-Jinnah Road, Johar Town, Lahore.
}

\begin{abstract}
The purpose of the study is to explore the preferred language learning styles of the undergraduate students based on their gender. In Pakistan, the traditional lecture method is most commonly used at the undergraduate level which is teacher centred (Hussain, Azeem \& Shakoor, 2011), and does not account for the learner and learning style differences. The difference in learning styles varies from one individual to another; thus, influencing the overall language learning process and performance (Manochehr, 2006). The present study used a mixed method approach, with Kolb's learning style model (1986) as the basis of the theoretical framework to determine individual learning styles. The sample of the study was selected through purposive sampling technique and comprised of 60 undergraduate students and 10 teachers who were teaching English to these students. Data was collected from the students studying English at the undergraduate level and their teachers by using survey questionnaire and semi structured interviews respectively. Data collected from the survey questionnaire and interviews was analysed in the form of descriptive statistics. The findings of the study confirmed that gender differences had a direct influence on the learning style preferences of the students. Moreover, both male and female students showed a tendency for Active Experimentation (AE) style of learning, indicating that they want to be actively engaged in their own learning process, instead of merely listening to the lectures being delivered in the traditional method. In addition, although the findings indicated that the teachers were aware of the differences in the learning styles based on gender, but their teaching practices did not account for the preferred learning styles of the students. These results can be further utilized to improve the teaching and learning styles for the students at the undergraduate students. Keywords: Learning styles, English Language learning, Gender differences.
\end{abstract}

DOI: $10.7176 /$ RHSS/10-19-06

Publication date:October $31^{\text {st }} 2020$

\section{Introduction}

This section highlights the background for the present study, in addition to the statement of the problem. Moreover, it provides a description of the research objectives and questions, significance, scope and the delimitations that were considered for this research.

\subsection{Background of the Study}

Learning styles characterize the psychological, cognitive and affective behaviors of a learner while indicating how an individual best perceives and learns from his environment and external sources around him (Felder \& Brent, 2005). Research has established that there are indeed differences in learning styles of students; some prefer to learn through visualizing and conceptualizing data that is presented to them, whereas others learn best by actively engaging in physical activities and undergoing new experiences (Kolb \& Kolb, 2018).

Furthermore, the interest in the field of gender studies and its relation to language learning has increased in the contemporary era. To establish a concrete relationship between the learning process and genetics of brain of male and female individuals has been a chief intent of such studies. A number of studies show that there are many neurological and anatomical differences in cognitive structure of both males and females (Kaiser, Haller, Schmitz $\&$ Nitsch, 2009) which in turn affects their cognitive abilities and language perceptions.

Earlier, the research showed complete and unwavering reliance on the theories of Universal Grammar and Innateness proposed by Noam Chomsky, which propagated the idea that all human beings are born with a language acquisition device that contains a mechanism for language perception and processing (Yang, 2004). So, it was assumed that all individuals, regardless of their gender, possess similar abilities for the perception and linguistic usage. However, recent studies have found marked differences among the cognitive and linguistic abilities of both male and female language users (Pavlenko, Blackledge \& Teutsch-Dwyer, 2011). This finding delineates the importance of revising the earlier reliance on Universal Grammar and Innateness theories by transforming the understanding of these ideas in the light of the contemporary research.

Many theories establish the connections between the difference in the learning styles in relation to cognition and gender which are helpful in understanding the overall learning process and uniqueness in learning styles of the learners. The Experiential Learning Cycle links cognition to individual learning styles and is used to determine preferred learning styles of adult learners (Kolb, 1976). It is based on the idea that learning is basically an experiential process which differs for each individual, owing to which they should be taught according to their 
preferred learning experiences.

While research established that there are indeed differences in learning styles and the approaches of students towards the overall learning process of language are unique, the focus of linguistic studies based on gender shifted towards the teaching methodologies and strategies. Since the syllabus and overall contents being taught to the students are the same, the differences arise, then, among the recipients that is, the male and female learners, and the way they are taught that content. Since a generic course design is followed for language syllabi in Pakistan (Aftab, 2004), therefore it falls upon the teachers to tailor that general course according to the individual needs and learning styles of their students.

Recent studies conducted in the domain of higher education in Pakistan have revealed that the student body is dissatisfied with the overall academic system in Pakistan and one of the major reasons contributing to this result is the lack of competent faculty members in the universities (Abbasi et al, 2011). This dissatisfaction is in terms of not only the competency of the teachers but also of their commonly used teaching methods that fail to account for gender differences when it comes to teaching a class comprising of both male and female students.

The current research aims to explore the difference in learning styles of undergraduate English language students based on their gender while assessing the teachers' perception and awareness of these unique learning approaches of their students. This understanding would be helpful in identification and further modification of the currently prevailing English language teaching strategies in order to offer best learning experience to the language learners at the undergraduate level.

\subsection{Statement of the Problem}

Individual differences in second language learning place gender as an important area of inquiry. Research has established that men and women exhibit many dissimilarities in terms of performance and learning styles in acquiring a second language (Kolb, 1984). However, such dissimilarities are not considered in the design of the language courses offered to students enrolled in Pakistani universities. Most of these courses are generic (Aftab, 2004) that do not take into account these varied learning styles. Moreover, the students have insufficient language support in English in higher education regarding the background of students, the facilities for English, the language needs and motivation of students for higher education, the availability and quality of English language courses, and the students' language outcomes (Mansoor, 2004). The analysis of factors likely to account for these differences is central to defining methodologies and strategies for effective teaching of English to the undergraduate students.

\subsection{Purpose of the Study}

The purpose of this study is to explore the perceptions of the language teachers regarding the learning styles of their undergraduate students in relation to gender. The awareness of the relationship between gender differences and the learning preferences of students is vital to developing a sound understanding of the overall learning process and its implications in the domain of pedagogy.

\subsection{Objectives of the Study}

The study investigating the learning styles of the students based on gender and the teachers' perceptions related to it had following research objectives:

- To investigate the learning styles of students in the English language classroom at the undergraduate level

- To identify the learning styles of students based on gender in the English language classroom at the undergraduate level

- To explore teachers' perceptions of learning styles of students in the English language classroom at the undergraduate level

\subsection{Research Questions}

The study investigating the learning styles of the students based on gender and the teachers' perceptions related to it answered the following research questions:

- What are the learning styles of students in the English language classroom at the undergraduate level?

- What are the learning styles of students based on gender in the English language classroom at the undergraduate level?

- What are the teachers' perceptions of learning styles of students in the English language classroom at the undergraduate level?

\subsection{Significance of the Study}

This study highlights the learning styles adopted by male and female learners to learn English language at undergraduate level. There is indeed a clear difference in the way different individuals learn, thus the idea of unique learning styles is concrete and becomes even more solid when viewed in the domain of education 
(Manochehr, 2006). Recent studies in the field of language learning and teaching suggest that a vast diversity of learning styles is brought by the students in the language classroom and teachers fail to acknowledge such differences due to which there is an impedance in the overall flow of learning of language students (Montgomery \& Groat, 1998).

Moreover, female students tend to be shyer and more hesitant, due to which they are reluctant to participate in the classroom (Alam \& Bashiruddin, 2013). This attitude is generally not considered by the teachers who continue to adhere to a fixed routine in their lectures while not focusing on the individual requirements of their male and female students. The present study offers a solution to this problem by identifying the already existing teaching methodologies and strategies adopted by English language teachers at universities.

\subsection{Delimitations of the Study}

The study is delimited to the students (male and female) studying English at the undergraduate level in a local university. Moreover, only those teachers were interviewed who were teaching the undergraduate students. In addition, the focus of the study was confined to only English language students and teachers.

\section{Literature Review}

Individual differences in second language learning place gender as an important area of inquiry in second language acquisition. To probe into the matter of language learning, it is first essential to look into what 'learning' actually means. According to one particular perspective, the individuals involved in the process of learning define it themselves on the basis of experiences they go through. Since everyone's experience of learning varies from the others, therefore, learning categories also fall into different ranges; it can be experiential or behavioral (Schmeck, 1988). Along similar lines, Kolb (1984) defined learning as a continuous process of experiential learning through which an individual creates their knowledge while undergoing certain experiences.

When it comes to language acquisition and learning, different individuals have different cognition and perception (Felder \& Brent, 2005) and therefore, possess unique learning styles and such differences are more pronounced when it is analyzed on the basis of gender.Repeated studies have proved that there are numerous neurological and anatomical differences in brain structure of both males and females (Kaiser, Haller, Schmitz \& Nitsch, 2009) which in turn affects their cognitive abilities and perceptions while learning and encountering a language. This suggests that males and females exhibit stark differences when it comes to cognition and perception due to different anatomy of their brains.

To cater to the subject of diverse learning styles of individuals, Reid (1987) classified learners into four categories namely visual, auditory, kinesthetic and tactile, which are based on the perceptions of learners. While assessing individual learning styles, students are typically asked to evaluate what sort of information presentation they prefer (e.g., words versus pictures versus speech) and what kind of mental activity they find to be most engaging (e.g., analysis versus listening) (Pashler et al, 2008).

Certain theories have been developed that establish connections between various learning styles and individual factors of learners; one prominent among these theories is Kolb's Experiential Learning Theory (ELT) which links cognition to individual learning styles. ELT defines learning as the process whereby knowledge is created through the transformation of experience; knowledge results from the combination of grasping and transforming experience (Kolb, 1984). It consists of dual levels; first level describes four stages of learning cycle while the second level deals with individual learning styles (Kolb, 1976). According to this theory, learning is most effective when learner undergoes the experience based on four stages: concrete experience, reflective observation based of the new experience, abstract conceptualization and active experimentation. Based on these four stages are defined four distinct learning styles namely diverging, assimilating, converging and accommodating, which as Kolb suggested, reflect and cater to the preferred way of learning by an individual. Whatever influences the choice of style, the learning style preference itself is actually the product of two pairs of variables, or two separate 'choices' that a learner makes ("Kolb's Learning Styles and Experiential Learning Cycle", 2008).

From a pedagogical viewpoint, there are various factors that contribute to overall learning progress of the students in a classroom; teacher effectiveness being primary among them. There are certain parameters that define teacher effectiveness and comprise of teacher experience, teacher preparation programs and degrees, type of teacher certification, specific coursework taken in preparation for the profession, and teachers' own test scores (Rice, 2003). Although teacher effectiveness is accounted as the most important factor for improvement of student performance, it is not made use of adequately. Teacher effectiveness is not evaluated or used to modify the already existing teaching practices (Weisberg et al, 2009), which suggests that there is exists a huge gap in mapping theory into practice. The results from research need to be implemented into pedagogy to ascertain the improvement of quality teaching for the student body.

In Pakistan, a research conducted on undergraduate and postgraduate medical students revealed a stark difference in learning styles of both. While undergraduates preferred activists and theorist approaches of learning, 
the postgraduates were mainly reflectors in terms of their learning styles. These differences in learning might arise due to sociocultural background of students but what is crucial is the fact that a multiplicity and profusion in terms of instructional design and assessment techniques is required to cater to these diverse styles of learning (Shukr, Zainab \& Rana, 2013).

The present study aims to investigate the differences in the learning styles of both genders at the undergraduate level. Moreover, it explores teachers' perceptions regarding these unique learning styles and investigates that how these language teachers employ various teaching strategies in order to cater to these differences in language perception and learning of their male and female students.

\section{Methodology}

\subsection{Research Design}

The study exploring different learning styles of undergraduate students based on their gender employed a mixed method approach. For this purpose, a quantitative analysis was carried out for students' learning styles with the help of a survey questionnaire while the perceptions of teachers were gauged through qualitative analysis of their interviews. Mixed method approach was used in this study in order to gather a holistic view of the learning styles of students and the extent to which the Pakistani language teachers of the undergraduate level are aware of them. Through the survey questionnaires based on Kolb's (1984) framework, the preferred learning styles of undergraduate students were identified. However, this alone was not adequate as the views of teachers were also crucial in knowing the complete academic picture of university level language students in Pakistan, due to which teacher interviews were also conducted.

\subsection{Theoretical Framework}

The study adopted Kolb's learning style model (1984) which was based on Experiential Learning Theory (ELT) developed by David A. Kolb. The learning style inventory (LSI) helps individuals understand their learning styles (Pedagogy, 2010), and was first published in 1971 and since then, many updated versions have been presented.

Kolb's ELT focuses on developing a learning model for adult development (Kolb, 2005), describing different learning styles and stages based on experiential learning for adult learners. While each individual possesses a unique, distinct and dominating learning style, however, it needs to be understood and emphasized that there is no wrong or right learning style; learning styles are not better or worse from each other, they are only different with respect to each other ("The Learning Style Inventory", n.d.).

This framework is based on the assumption that there are four basic stages involved in the process of learning; the foremost stage is occupied by experience. Initially, the learner is exposed to a new experience in the first stage of learning, moving on to the second and third stages, he reflects and thinks about that recently acquired experience. Finally, the last stage is of action that closes and seals the learning process built around that particular experience. Therefore, these four stages comprise the basic preferred learning styles of students in Kolb's LSI as:

- $\quad$ Concrete Experience (CE)

- Reflective Observation (RO)

- Abstract Conceptualization (AC)

- Active Experimentation (AE)

According to Kolb's ELT, these four processes are occurring continuously and simultaneously in all the learners; what is unique in each learner is the preferred mode of acquiring and approaching new information and experiences among all these four processes. CE type learners learn best through trial and error situations and display a high tendency of interpersonal relationship with those around them. According to Kolb (1984), CE describes learning as full and open involvement in the learning process without any bias cloud the judgement of the learners regarding any new experiences. As the name suggests, RO type learners are keen observers and pay meticulous heed to all the details. On the other hand, AC type learners prefer to 'conceptualize' things and their focus is more theory oriented. Lastly, AE type learners exhibit a kinesthetic approach towards learning, requiring to be actively engaged in activities to enhance their learning process (Majd \& Pishkar, 2017).

In terms of categorical learning styles, diverging learners are characterized as 'feeling and watching' type, as they display a combination of CE/RO type properties in their learning approaches. According to McLeod (2010), these learners prefer to watch and gather new information or experience presented to them, instead of practically doing anything with it.

The next learning style is assimilating which is combination of $\mathrm{AC} / \mathrm{RO}$; these learners require a concrete description and deliverance of concepts and ideas to them in order to fully familiarize themselves with any given task or information. Converging learners, on the other hand, combine AC/AE properties and learn best by thinking and doing; they find practical uses for theories and ideas they are exposed to. Finally, accommodating learners are both 'doing and feeling' as they display a combination of properties of CE/AE. This type of learners are the ones that need hands on experience and display a preference for practical approach towards learning (McLeod, 2010).

In the present study, this framework was adopted to explore the learning styles of the male and female 
undergraduate students studying English due to its suitability of context for adult learners. The undergraduate language students were asked to fill the Learning Style Inventory (LSI) questionnaire according to their preferred learning styles. Regarding higher education, the focus should be on the learners improving and modifying their knowledge base through connected experiences and re-learning by the use of effective feedback from their teachers (Kolb, 2013).

\subsection{Sample}

The sample of the study includes:

- 60 students studying English at the undergraduate level in a university in Pakistan

- 10 Language teachers, teaching English to the undergraduate students in a university in Pakistan

The sampling technique used for this study was purposive sampling because it aims to explore the learning styles of male and female students enrolled in first and second semester of undergraduate programs. In addition, the undergraduate level was selected as the level of study for the present research owing to the fact that students in Pakistan are met with a different learning environment as they step into undergraduate programs from their intermediate studies at college level (Rahbar et al, 2001).

\subsection{Data Collection Tools}

Data for exploring learning styles of undergraduate male and female students was collected through survey questionnaires and semi-structured interviews.

- Questionnaires were adopted from the theoretical framework of Kolb's learning styles owing to their relevance to the level of learners i.e. undergraduate students. In the present study, questionnaires consisting of 40 items based on Kolb's LSI for determining preferred learning styles were distributed among students to be filled out by them.

- An interview protocol was developed for the conduction of semi-structured interviews from the language teachers who taught English to these undergraduate male and female students (See Appendix B).

\subsection{Data Collection Procedures}

Data collection for individual learning styles of undergraduate students consisted of two parts.

- For the quantitative study of learning styles, male and female students were asked to fill out questionnaires developed in line with Kolb's theoretical framework. The questionnaires were pilot tested and then selfadministered for the conduction of the study.

- During the qualitative analysis, interviews of language teachers were conducted to measure the use of their teaching strategies according to individual learning styles of students based on gender. The interview comprised of 5 questions and lasted for approximately 10 minutes for each participant. The responses of all the participants were recorded digitally.

\subsection{Data Analysis}

The data collected through the mixed method study for exploring learning styles of male and female students was analysed through descriptive statistics.

- The data from questionnaires was analysed to explore learning styles of male and female students at the undergraduate level. The data was interpreted in terms of graphs to indicate the different learning style preferences of undergraduate students. Additionally, these statistics were further divided into two categories based on gender to show the preferred learning styles of male and female undergraduate students studying English.

- The data acquired through interviews of the faculty was used to infer perceptions of teachers regarding their teaching strategies to take into account the individual learning demands of their male and female students. These perceptions gained through the faculty interviews were used by the researcher to relate whether the use of current strategies by these teachers is effective in terms of preferred learning styles of undergraduate students or not.

These varied stages of data analysis assisted in comprehending the diverse aspects that are involved in the learning process of the undergraduate language students and how it can be used to improve the teaching process for male and female learners at the undergraduate level.

\subsection{Reliability}

Reliability of the survey questionnaire for this study was established by pilot testing the survey questionnaire 5 participants from the population (other than the sample) with the purpose of removing the inconsistencies occurring within the questionnaire in case the participants had confusions in understanding the given questions. The students were asked to read the instructions given at the beginning of the questionnaire and fill it according to 
the directions. In case of being unable to comprehend any word or being unclear about the instructions, they were to report it to the researcher. After the pilot testing, and the required changes the survey questionnaire, was administered to the actual sample of the study.

\subsection{Ethical Considerations}

The following ethical considerations were kept in mind while conducting this study:

- All necessary documentation and permissions were obtained before the conduction of survey and interviews.

- $\quad$ The participants were briefed about the purpose of the interview and were informed beforehand that their interviews will be recorded digitally and transcribed later for data analysis.

- The participation in the research was voluntary; participants could withdraw from the study at any time.

- The data collected was confidential and to be used for research purposes only.

- The identity of all the participants was kept anonymous.

\section{Results and Findings}

\subsection{Results of Learning Styles Survey}

The survey was a self-administered questionnaire administered to learners studying English in their first and second semesters of undergraduate studies in a private sector university in Lahore. The results obtained from questionnaire were formulated in the form of tables demonstrating percentages divided into four categories. The categorical division was based on Kolb's LSI (1984) and classifies learning preferences as Concrete Experience (CE), Reflective Observation (RO), Abstract Conceptualization (AC) and Active Experimentation (AE) types. Figure 1 illustrates the overall result of preferred learning styles of undergraduate students studying English.

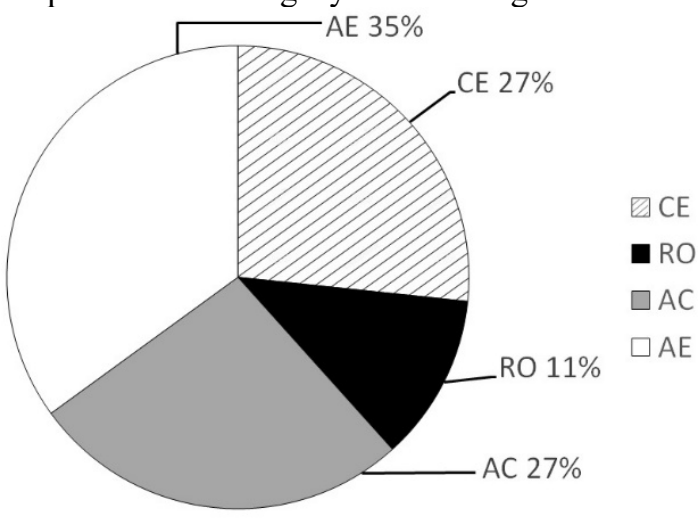

Figure 1 English Language Learning Preferences of Undergraduate Students

The results in Figure 1 show the percentage of students and their preferences for specific leaning toward the four learning styles categories as classified by Kolb (1984). The results show a concentration of students in the AE category grouping with $35 \%$, while a similar preference of $27 \%$ for the CE and AC categories was shown by the undergraduate students. On the other hand, the results show a comparatively smaller percentage of students, leaning towards the RO category with $11 \%$.

These results indicate that for a majority of students in the study, the inclination towards the Active Experimentation (AE) learning style was higher, while the least preferred learning approach was found to be the Reflective Observation, suggesting that the majority of undergraduate students fit into the Accommodating class and are termed as Activists, signifying learners who actively engage in their learning process instead of only focusing on theoretical knowledge provided in the class. The least preferred RO category by the undergraduate students suggests that the general lecture design lacked such procedures and activities that promoted self-refection and critical thinking on the part of the learners when they had learned something new.

Moderate preference was shown by the students towards both $\mathrm{CE}$ and $\mathrm{AC}$ categories of learning, indicating that apart from being actively engaged in their learning process, the students also preferred to build their conceptual base by listening keenly to the information provided to them through classroom lectures. Such students fall into the Converging and Diverging class of learning styles as categorized by Kolb (1984).

\subsubsection{Identification of Learning Styles Based on Gender}

The survey questionnaire was self-administered on the undergraduate students to identify their learning style preferences. The results of survey questionnaire when examined for gender differences, revealed that the males and females have different learning styles and, show a preference for learning in their own unique ways. Figure 2 illustrates the comparison statistics for learning style preferences corresponding to gender. 


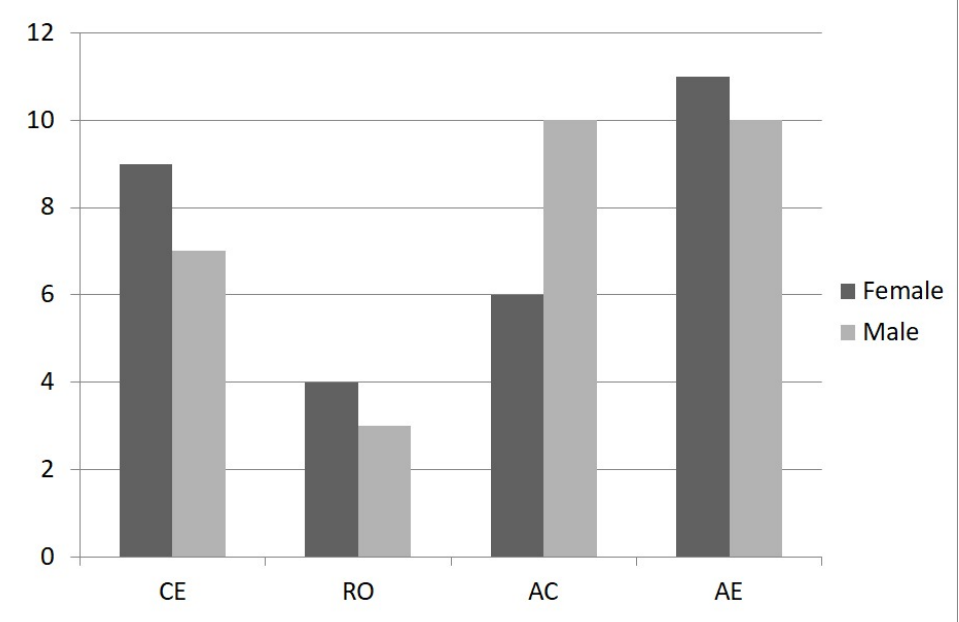

Figure 2 Gender Based Learning Styles Comparison of Pakistani Undergraduate Students

The results shown in the Figure 2 reveal that while the female learners showed a preference for the $\mathrm{AE}$ category, the male students, on the other hand, displayed an equal preference for both $\mathrm{AE}$ and $\mathrm{AC}$ categories, suggesting that both the male and female students possessed an inclination towards activist and kinesthetic approach in their learning styles, in order to become active participants in their own learning processes. On the other hand, $\mathrm{CE}$ was identified as the second most preferred learning style category by female learners, whereas the male learners opted for AC category as their second most preferred learning style. This finding indicates that although all the learners opted for an actively engaging learning style, both male and female learners showed a tendency for the need to know and grasp knowledge and strengthen their conceptual base. The results also show that the least preferred style by both the male and female undergraduate students was the RO category, demonstrating that the students showed a more positive tendency towards activity and experience-based learning and were less inclined to engage in learning styles based on reflective observation and thinking.

\subsection{Findings}

This section deals with the findings from the interviews of the language teachers. The interviews were conducted to explore their perceptions of the learning styles of undergraduate students and were based on questions (See Appendix 2) regarding differences in learning styles and the use of language and academic performance in relationship to the gender. In addition, the teachers were asked to describe their personal teaching styles in the language classroom. Moreover, the teacher interviews served as a basis to draw generalizations on whether the teaching methodologies and strategies used by the language teachers were effective in providing appropriate explanations for the individuality and uniqueness of learning styles for a diverse group of students.

\subsubsection{Individual Learning Styles}

When inquired about the differences in the learning styles of students, the teachers agreed that there were distinct and unique learning styles exhibited by their students in the language classroom. Some of the teachers were of the view that different students showed partiality for specific learning style; with some favouring the kinaesthetic approach preferring to actively engage in physical activities, while a majority of the students prefer the auditory approach; listening carefully to the lectures in class. One of the teachers stated that "My students are habitual of listening to lectures and learning through the use of audio/visual aids" (T9). This remark implies that there was a general consensus by the teachers that all categories of learners showed better and improved understanding of the lectures that were delivered orally, while combined with the use of audio/visual aids, thus displaying a tendency for concrete conceptualization.

\section{Effect of gender on learning styles}

When asked about the association of gender with learning styles of individuals, majority of the teachers reported that gender does have an effect on learning styles of the undergraduate students and that male and female students displayed different preferences towards learning processes. Almost all the teachers agreed that the most common trait of learning exhibited by female students is note-taking; T5 stated that female students "keep taking notes during the whole lecture, all the time, sometimes without even blinking their eyes". Other teachers also supported this claim that females in their language class do display a vigorous and keen interest in note-taking during their lectures.

On the contrary, there were two teachers who claimed that they did not witness any effect of gender on the learning styles of individuals. One among them speculated that the learning styles "varied from person to person and were not based on gender differences" (T2). Similarly, another teacher argued that "it's not about gender 
differences; it's about responsible and irresponsible students" (T3), suggesting that there were students who took their learning process seriously and were willing to put more effort into learning, while there were others that displayed negligent behaviour owing to lack of motivation and therefore, did not take much responsibility for their own learning.

In addition to this, majority of the teachers agreed that male students exhibited kinaesthetic mode of learning; they were more interested in active participation and indulging in physical activities instead of listening to the lectures being delivered through traditional modes of oral or PowerPoint presentations. While females displayed keen interest in reading and writing new information and material presented to them, male students did not prefer to read or take notes.

These findings indicate that since male and female students tend to learn differently, so they exhibited different behavioral traits while learning under the given conditions of the classroom. It can also be implied that since the teaching style of the teachers was not tailored according to the learning style based on the gender of the students, so the students were not completely engaged in the classroom and displayed signs of boredom and laziness.

\subsubsection{General Teaching Styles}

During the interviews, the language teachers were asked to identify and explain their teaching styles that they adopt in their classroom and lectures. The findings indicate that different teachers made use of different teaching methodologies for the sound delivery of their lectures to the undergraduate students. Some of the teachers believed in interactive teaching; they felt that it is an essential requirement of effective teaching, to keep their students engaged at all times, and to keep interacting with them through multiple ways. Similarly, one teacher also stated that he maintained an interactive style of teaching in his language classroom while "making jokes and being jolly to keep the students engaged and interested in the lecture" (T7). This remark is indicative of the availability of limited interactive strategies to the teachers, owing to which these teachers resort to cracking jokes and maintaining a light atmosphere in the class. The teachers reported to often indulge their students into funny discussions and brief chit chat in order to keep them attentive, while actively participating in their own learning process.

On the other hand, one of the teachers maintained that she employed eclectic approach of teaching in her class, to "cater to all the different styles as students have different learning styles" (T4), suggesting that it is important to make use of a range of strategies and an amalgam of methodologies in the classroom to take into account the learner differences. Similarly, another teacher also reported the use of the same approach towards teaching in his classroom "by making use of a varied range of strategies and techniques; from delivery of lectures to engaging the students in interactive tasks and providing them with feedback" (T9). This suggests that the language teachers at the undergraduate level were well aware of the demands of their students as they kept using a variety of strategies and pedagogical techniques in order to take into account the learner differences in their classrooms.

In addition, many teachers reported that they made use of traditional methods of teaching in their class, i.e. by delivering lecture orally to the students and seldom making use of whiteboard or PowerPoints, thus preferring "to teach through lectures since it is the subject's demand" (T8), suggesting that the teachers felt that some subjects were too focused on theory and had to be taught through conventional methods of teaching. Moreover, these abovementioned teaching styles of the language teachers indicate that a diversity of teaching styles exists in the language classroom at the undergraduate level; different teachers employed different methodologies that they thought were best suited for their students' needs.

\section{Conclusion}

This research aimed to investigate the distinct learning styles of Pakistani undergraduate students while exploring the learning preferences in association with their gender. The results synthesized from this study revealed that Pakistani undergraduate students display varied learning styles owing to individual preferences of learning and a diversity of the educational and social backgrounds. Moreover, most of them opted for AE learning style, which was found to be equally preferred by both the male and female learners of the undergraduate level. On the other hand, the male and female students exhibited different tendencies for the remaining three categories (AC, RO and $\mathrm{CE}$ ) of learning styles, signifying that learning style preferences slightly varied regarding gender differences.

Additionally, another objective of the study was to gauge the perceptions of the language teachers at the undergraduate level in Pakistan regarding individual learning styles of their students. Through the teachers' interviews, it was found that the language teachers at the undergraduate level in Pakistan are aware of the different learning styles of their students as they pointed out varied learning preferences existed among their students. Also, the teachers reported that the male and female students demonstrated distinct styles and strategies of learning in the classroom, indicating that learning styles do vary across genders.

However, regarding their teaching styles and strategies, Pakistani teachers need to modify their current practices which are lacking in terms of clear evaluation of the preferred learning styles of their students; the language teachers do not take into account the inclination of their undergraduate students towards a more actively 
engaging and kinesthetic approach of learning. Although the teachers acknowledged the existence of distinct learning styles for the male and female undergraduate students, yet their teaching styles were not found to include any strategies or activities targeted specifically to address the demands of their students based on gender, highlighting the strong need of rectifying and updating their teaching styles.

The research findings were in line with the conclusions drawn by Obiefuna and Oruwari (2015), who suggested that the styles of learning vary from individual to individual since every person's cognitive, social and educational backgrounds are different. Also, this research identified a mismatch between the current teaching practices and the preferred learning styles of the undergraduate students in Pakistan, which is consistent with Peacock's (2001) claim that ESL learners face demotivation and slowed pace of learning owing to an imbalanced approach of their teachers that fails to take into account the ways their learners learn best. As pointed out by Chamot (2014), to modify their practices and design specifically tailored strategies for both male and female students is the responsibility of the teachers; this research also pointed out the gap that currently exists in the pedagogy at the undergraduate level in Pakistan in terms of accounting for the unique styles of learning of the male and female students.

\subsection{Limitations}

- The study was limited to the undergraduate students; hence the results of this study cannot be generalized for the primary or secondary level students.

- Another limitation of this study is that it investigated the learning styles of the English language students. Further studies can be conducted to confirm whether similar results are obtained for the learners studying in other disciplines like Sciences or Arts.

\subsection{Suggestions for Future Research}

The findings of this study suggest that research into teacher education and training should integrate the evaluation of individual students learning style in order to provide them with an effective learning experience directed towards the way they learn best. Similar research can also be done with larger samples in different settings to be able to generalize the results. In addition, future research can also focus on the relationship between learning styles and performance. In this regard, it is yet to be investigated whether the high achieving students belonging to only a specific category of learners.

\section{References}

Abbasi, M. N., Malik, A., Chaudhry, I. S., \& Imdadullah, M. (2011). A study on student satisfaction in Pakistani universities: The case of Bahauddin Zakariya University, Pakistan. Asian Social Science, 7(7), 209.

Aftab, A. (2012). English language textbooks evaluation in Pakistan (Doctoral dissertation, University of Birmingham)

Alam, Q., \& Bashiruddin, A. (2013). Improving English oral communication skills of Pakistani public school's students. International journal of English language teaching, 1(2), 17-36.

Chamot, A. U. (2004). Issues in language learning strategy research and teaching. Electronic journal of foreign language teaching, 1(1), 14-26.

David Kolb's Learning Cycle. $\quad$ (n.d.). Retrieved from https://teach.its.uiowa.edu/sites/teach.its.uiowa.edu/files/docs/docs/David_Kolbs_Learning_Cycle_ed.pdf

Felder, R. M., \& Brent, R. (2005). Understanding student differences. Journal of engineering education, 94(1), 5772.

Hussain, A., Azeem, M., \& Shakoor, A. (2011). Physics teaching methods: scientific inquiry vs traditional lecture. International Journal of Humanities and Social Science, 1(19), 269-276.

Kaiser, A., Haller, S., Schmitz, S., \& Nitsch, C. (2009). On sex/gender related similarities and differences in fMRI language research. Brain research reviews, 61(2), 49-59.

Kolb, A. Y. (2005). The Kolb learning style inventory-version 3.12005 technical specifications. Boston, MA: Hay Resource Direct, 200, 72.

Kolb, D. A. (1976). Learning style inventory technical manual. Boston, MA: McBer.

Kolb, D. A. (2013). The Kolb Learning Style Inventory 4.0: Guide to Theory. Psychometrics, Research \& Applications.

Kolb, A., \& Kolb, D. (2018). Eight important things to know about the experiential learning cycle. Australian Educational Leader, 40(3), 8.

Kolb's Learning Styles. (n.d.). Retrieved from https:/www.businessballs.com/self-awareness/kolbs-learningstyles/

Lai, C. C., \& Kuo, M. M. (2007, March). Gender differences in CALL programs for English as a second language acquisition. In Society for Information Technology \& Teacher Education International Conference (pp. 28332836). Association for the Advancement of Computing in Education (AACE). 
Majd, E., \& Pishkar, K. (2017). An Investigation into the Relationship between Kolb's Learning Styles and Learning Idioms among Iranian ELT Students. Journal of Applied Linguistics and Language Research, 4(1), 213-225

Manochehr, N. N. (2006). The influence of learning styles on learners in e-learning environments: An empirical study. Computers in Higher Education Economics Review, 18(1), 10-14.

Mansoor, S. (2004). TEFL in Pakistan: Emerging issues. The Journal of AsiaTEFL, 1(1), 349-374.

McLeod, S. (2010). Kolb - $\quad$ Learning $\quad$ Styles. $\quad$ Retrieved from http://cei.ust.hk/files/public/simplypsychology_kolb_learning_styles.pdf

Montgomery, S. M., \& Groat, L. N. (1998). Student learning styles and their implication for teaching (Vol. 10). Centre for Research on Learning and Teaching, University of Michigan.

Obiefuna, C. A., \& Oruwar, J. N. (2015). Students' learning styles and their performance in English language in senior secondary schools in Imo State, Nigeria. African Educational Research Journal, 3(4), 230-237.

Pashler, H., McDaniel, M., Rohrer, D., \& Bjork, R. (2008). Learning styles: Concepts and evidence. Psychological science in the public interest, 9(3), 105-119.

Pavlenko, A., Blackledge, A., Piller, I., \& Teutsch-Dwyer, M. (Eds.). (2011). Multilingualism, second language learning, and gender (Vol. 6). Walter de Gruyter.

Peacock, M. (2001). Match or mismatch? Learning styles and teaching styles in EFL. International Journal of Applied Linguistics, 11(1), 1-20.

Pedagogy, V. (2010). Do they really get it? Using the Kolb LSI to reach every student. Journal of Singing, 66(4), 421-427.

Rahbar, M. H., Vellani, C., Sajan, F., Zaidi, A. A., \& Akbarali, L. (2001). Predictability of medical students' performance at the Aga Khan University from admission test scores, interview ratings and systems of education. Medical education, 35(4), 374-380.

Reid, J. M. (1987). The learning style preferences of ESL students. TESOL quarterly, 21(1), 87-111.

Rice, J. K. (2003). Teacher quality: Understanding the effectiveness of teacher attributes. Economic Policy Institute, 1660 L Street, NW, Suite 1200, Washington, DC 20035.

Schmeck, R. R. (1988). An introduction to strategies and styles of learning. In Learning strategies and learning styles (pp. 3-19). Springer, Boston, MA.

Shukr, I., Zainab, R., \& Rana, M. H. (2013). Learning styles of postgraduate and undergraduate medical students. J Coll Physicians Surg Pak, 23(1), 25-30.

The Learning $\quad$ Style Inventory. $\quad$ (n.d.). Retrieved from http://med.fau.edu/students/md_m1_orientation/M1\%20Kolb\%20Learning\%20Style\%20Inventory.pdf

Weisberg, D., Sexton, S., Mulhern, J., Keeling, D., Schunck, J., Palcisco, A., \& Morgan, K. (2009). The widget effect: Our national failure to acknowledge and act on differences in teacher effectiveness. New Teacher Project.

Yang, C. D. (2004). Universal Grammar, statistics or both?. Trends in cognitive sciences, 8(10), 451-456. 